\title{
APRISIONAMENTO PARENTAL NO BRASIL - UM ESTUDO METANALÍTICO
}

PARENTAL IMPRISONMENT IN BRAZIL - A METHANALYTIC STUDY

\section{Claudia Gomes de Castro', Maria de Lourdes Mattos Barreto}

RECEBIDO EM: 16/03/2018 | ACEITO EM: 12/11/2018

DOI: $10.5902 / 2317175831692$

\section{RESUMO}

O presente artigo analisa teses e dissertações que investigaram as implicações do aprisionamento parental em âmbito familiar, tomando como base de consulta a Biblioteca Nacional de Teses e Dissertações dos principais programas de pós-graduação das Universidades Brasileiras entre 2006 e 2016. Busca-se trabalhar esse tema, realizando uma revisão sistemática nos moldes propostos por Cooper (2010) e detalhado em artigo científico por Figueiredo Filho e outros (2014), que envolvem a abordagem metodológica, tipos de pesquisa, métodos de coleta e análise dos dados, autores que mais produzem na área e referências mais usadas. Os resultados demonstram que o tema ainda é pouco estudado pelos programas de pós-graduação no Brasil, sobretudo quando se trata de dar voz a crianças e adolescentes envolvidos nessa situação.

Palavras-chave: Revisão sistemática; Metanálise; Aprisionamento parental; Encarceramento familiar.

\footnotetext{
1 Doutoranda em Economia Doméstica (Famílias, Políticas Públicas e Desenvolvimento Humano e Social) na Universidade Federal de Viçosa; mestre em História e Culturas Políticas pela Universidade Federal de Minas Gerais (2006); bacharel em Direito pela Universidade Federal de Vicosa (2014); bacharel em Comunicação Social/ Jornalismo pelo Centro Universitário de Belo Horizonte-UNI-BH (2001), ; e Diploma Superior de Espanhol como Língua Estrangeira - DELE (2006).

2 Possui graduação em Economia Doméstica pela Universidade Federal de Viçosa (1986), mestrado em Educação pela Universidade Estadual de Campinas (1996) e doutorado em Educação pela Universidade Estadual de Campinas (2001). Atualmente é professora Associada IV (DR) da Universidade Federal de Viçosa.
} 


\begin{abstract}
This article analyzes theses and dissertations that investigated the implications of parental imprisonment in the family context, based on the Biblioteca Nacional de Teses e Dissertações, of the main postgraduate programs of the Brazilian Universities between 2006 to 2016. We seek to work this a systematic review, as proposed by Cooper (2010) and detailed in a scientific paper by Figueiredo Filho et al (2014), which involve the methodological approach, types of research, methods of data collection and analysis, authors that producente the most in the area and the most used references. The results demonstrate that the subject is still little studied by the graduate programs in Brazil, especially when it comes to giving voice to children and adolescents involved in this situation.
\end{abstract}

Keywords: Systematic review; Meta-analysis; Parental imprisonment; Family incarceration.

\title{
1 Introdução
}

Este artigo nasceu da necessidade de se conhecer como os pesquisadores brasileiros vêm abordando a questão do aprisionamento parental e suas consequências em âmbito familiar. Mais especificamente, ensejava-se descobrir se as crianças e adolescentes envolvidos nesses dramas familiares têm sido consideradas como objeto de estudo e, em caso afirmativo, qual a abordagem trabalhada pelos pesquisadores nos últimos anos. Para tanto, considerou-se que a realização de uma revisão sistemática, por meio de metanálise, possibilitaria o contato atualizado com essas produções e abriria um leque de referenciais para a composição de uma tese acadêmica. Isto posto, foram revelados uma série de dados que serão apresentados na sequência.

De acordo com dados fornecidos pelo Departamento Penitenciário Nacional (DEPEN) ${ }^{3}$ e divulgados pelo Ministério da Justiça e Segurança Pública em 2016, a população carcerária no Brasil é de, aproximadamente, 700 mil pessoas, cumprindo diversas modalidades de pena. Com a $4^{\mathrm{a}}$ maior população carcerária do mundo, estima-se que 6 em cada 10 pessoas privadas de liberdade possuem, pelo menos, 1 filho. Em meio à opinião pública, que clama por justiça e segurança, e ao cumprimento da sentença, muitas vezes em estabelecimentos que não oferecem condições mínimas de dignidade, está a delicada relação familiar entre crianças, adolescentes e seus pais aprisionados.

Em uma das pesquisas pioneiras no Brasil sobre encarceramento parental, Stella (2006) adverte que as implicações do aprisionamento de pais ou mães na vida de seus filhos ainda é um problema social ignorado, tanto pela literatura acadêmica, quanto pelos agentes de políticas públicas brasileiras. Não obstante, alguns trabalhos nas áreas de Ciências Sociais Aplicadas, sobretudo na Psicologia, discutirem a temática da separação, involuntária ou não, de pais e filhos, a questão do encarceramento parental ainda é pouco difundida nos meios acadêmicos nacionais, sendo os Estados Unidos o país de onde provém a maior parte da bibliografia sobre o tema.

3 Dados disponíveis em <http://www.justica.gov.br/noticias/mj-divulgara-novo-relatorio-do-infopen-nestaterca-feira/relatorio-depen-versao-web.pdf> 
Mesmo se tratando de um tema pouco estudado no Brasil, ao propor uma pesquisa acadêmica, sobretudo na área de ciências sociais aplicadas, deve-se ter em mente que o assunto a ser trabalhado não é um fato inédito ou uma descoberta genuína, mas sim uma outra maneira de "olhar" para aquele objeto de estudo. Dessa forma, o pesquisador pode deparar-se com uma enorme disponibilidade de dados que, analisados aleatoriamente, conduzem a erros significativos de abordagem teórica e/ou metodológica. A revisão sistemática torna-se, assim, uma ferramenta de grande relevância, pois permite ao leitor ter acesso a uma síntese atualizada de vários estudos acerca de um mesmo tema, em um só trabalho, tornando obsoleta a consulta a trabalhos mais antigos. Ademais, a compilação de dados permite ao pesquisador justificar a propositura do tema a ser trabalhado, apresentando os pontos inovadores da ideia que se defende e ampliando sua base teórica (FIGUEIREDO FILHO et al, 2014).

Para Legramanti e Klarmann (2011), ao combinar resultados originários de distintas pesquisas, a revisão sistemática produz estimativas que aglutinam o todo. É neste sentido que a metanálise apresenta-se como uma revisão sistemática eficaz, combinando resultados de diferentes fontes em estimativas, chamadas de meta-analíticas, capazes de sintetizá-las em um mesmo banco de dados. Compartilhamos, dessa forma, do conceito de metanálise defendido por Roscoe e Jenkins (2005), que a define como o processo de alocação de distintas pesquisas em um mesmo banco de dados, empregando métodos analíticos e estatísticos para obter uma variedade de dados referentes aos fatores equivalentes nos estudos. Para a feitura desta metanálise, optou-se por adotar como procedimento metodológico a divisão em estágios, desenvolvida por Cooper (2010) e detalhada em artigo científico por Figueiredo Filho e outros (2014), conforme as etapas seguintes.

\section{2 - Iniciando uma metanálise: identificação do problema de pesquisa, coleta da literatura e dos dados}

De acordo com Cooper (2010); Figueiredo Filho e outros (2014), toda pesquisa científica, bem como a pesquisa metanalítica, deve oferecer uma descrição do problema a ser estudado. O primeiro passo, então, é elucidar, de forma clara e objetiva, o problema que despertou o interesse em pesquisar determinada temática. Dessa forma, é importante destacar, uma vez mais, a questão primordial deste trabalho: como a academia brasileira vem trabalhando as implicações do aprisionamento parental em âmbito familiar?

Estabelecido o problema, segue-se para o seguinte estágio, no qual importa entender que a pesquisa metanalítica segue os mesmos parâmetros de uma pesquisa empírica, sendo necessário, portanto, que o pesquisador defina previamente a sua amostragem, explicitando os critérios adotados ao definir sua seleção de dados (FIGUEIREDO FILHO et al, 2014). Isto posto, elegeu-se o 
Banco de Teses do Instituto Brasileiro de Informação em Ciência e Tecnologia (IBICT), que é um mecanismo de busca das Bibliotecas Digitais de Teses e Dissertações (BDTD) das universidades brasileiras, por se tratar de um banco de dados com acesso somente às teses e dissertações que foram defendidas publicamente e que, por conseguinte, já passaram pelo crivo de uma banca. Por meio desse mecanismo, refinou-se as buscas em um período de dez anos, correspondendo aos anos entre 2006 e 2016, por se acreditar que os trabalhos dentro desse marco cronológico podem trazer dados e referencial bibliográfico mais atualizados acerca do problema proposto.

Definida a amostragem e o período a ser pesquisado, iniciou-se a construção de uma base de dados particular a partir das buscas realizadas nos resumos de dissertações e teses pelas seguintes palavras-chaves nos idiomas português, inglês e espanhol, respectivamente: aprisionamento parental, encarceramento familiar; parental imprisonment, incarcerated parents; encarcelamiento parental, encarcelamiento familiar. Em seguida, passou-se para avaliação da qualidade dos estudos encontrados, etapa que consiste no exame minucioso do grau de correspondência entre os métodos e as técnicas utilizadas na coleta de informações para a elaboração das próprias conclusões (COOPER, 2010). Segundo Figueiredo Filho e outros (2014), dentre as técnicas mais comuns utilizadas nessa fase, encontra-se a prática de confrontar a frequência dos achados que foram estatisticamente significativos.

Por conseguinte, após a montagem da base de dados particular, tomouse cada trabalho de forma individual para uma análise dos recortes adotados por cada autor ao trabalhar a questão do aprisionamento familiar. Neste sentido, a metodologia empregada por cada um deles, com destaque para a amostra e o referencial bibliográfico, contribuiu para os resultados obtidos e a consistência dos dados. Deste modo, além de averiguar quais foram as obras e seus respectivos autores mais citados nas pesquisas, traçou-se, também, uma correspondência dos estudos, ano e local de publicação, e metodologia empregada. Para isso, estabeleceu-se que a forma mais prática e eficaz de chegar a esses resultados é por meio da tabulação dos dados em software estatístico e, assim, optou-se por empregar o Excel nessa jornada.

Iniciada, então, a coleta e tabulação dos dados, a revisão sistemática no IBICT revelou dez trabalhos defendidos entre 2006 e 2016 com referência ao tema aprisionamento parental ou encarceramento familiar. Esse resultado comprovou que a academia brasileira tem voltado seus olhares à problemática proposta com variadas abordagens metodológicas. Ademais, foi possível identificar os métodos de coleta e de análise dos dados mais empregados, bem como as amostras trabalhadas e seus respectivos recortes, conforme representado no Quadro 1: 
Quadro 01: Relação de estudos x programa x amostra x recorte x metodologia

\begin{tabular}{|c|c|c|c|c|}
\hline AUTOR/ANO & $\begin{array}{l}\text { PROGRAMA DE } \\
\text { PESQUISA }\end{array}$ & AMOSTRA & RECORTE & $\begin{array}{l}\text { METODOLOGIA } \\
\text { APLICADA }\end{array}$ \\
\hline SILVA, A. D.; 2014 & $\begin{array}{l}\text { Mestrado em Serviço } \\
\text { Social UESJM }\end{array}$ & $\begin{array}{l}\text { Mulheres reclusas da } \\
\text { Cadeia Pública Feminina } \\
\text { de Franca }\end{array}$ & $\begin{array}{l}\text { Compreender as } \\
\text { implicações do } \\
\text { encarceramento da } \\
\text { mulher chefe de família } \\
\text { monoparental }\end{array}$ & $\begin{array}{l}\text { Qualitativa/Análise de } \\
\text { conteúdo }\end{array}$ \\
\hline ABRÃO, M. J.; 2010 & $\begin{array}{l}\text { Mestrado em Educação } \\
\text { USP }\end{array}$ & $\begin{array}{l}\text { Crianças e adolescentes } \\
\text { do abrigo MAESP }\end{array}$ & $\begin{array}{l}\text { Averiguar e } \\
\text { compreender as relações } \\
\text { sociais entre família e } \\
\text { abrigo }\end{array}$ & $\begin{array}{l}\text { Qualitativa/ } \\
\text { Etnografia }\end{array}$ \\
\hline $\begin{array}{l}\text { VIEIRA, C. M. C. de A.; } \\
2013\end{array}$ & $\begin{array}{l}\text { Doutorado em Direito } \\
\text { UFSC }\end{array}$ & $\begin{array}{l}\text { Mulheres reclusas e } \\
\text { seus filhos do Centro de } \\
\text { Progressão Penitenciária } \\
\text { do Butantan }\end{array}$ & $\begin{array}{l}\text { Compreender a infância } \\
\text { dentro do presídio à luz } \\
\text { da doutrina da proteção } \\
\text { integral }\end{array}$ & $\begin{array}{l}\text { Qualiquanti/ } \\
\text { Método dedutivo }\end{array}$ \\
\hline $\begin{array}{l}\text { BECKMAN, M. V. R.; } \\
2007\end{array}$ & $\begin{array}{l}\text { Mestrado em Psicologia } \\
\text { PUC Campinas }\end{array}$ & $\begin{array}{l}\text { Crianças de um } \\
\text { centro educacional de } \\
\text { Campinas cujos pais } \\
\text { encontravam-se presos }\end{array}$ & $\begin{array}{l}\text { Compreender o } \\
\text { desenvolvimento de } \\
\text { crianças em idade } \\
\text { pré-escolar, filhas de } \\
\text { presidiários a partir da } \\
\text { percepção de familiares. }\end{array}$ & $\begin{array}{l}\text { Qualitativa/ } \\
\text { Observação participante }\end{array}$ \\
\hline QUADRADO, J. C.; 2014 & $\begin{array}{l}\text { Doutorado em } \\
\text { Sociologia UnB }\end{array}$ & $\begin{array}{l}\text { Mulheres que } \\
\text { cometeram violência e } \\
\text { infrações penais e que } \\
\text { estavam na Unidade } \\
\text { Prisional Feminina de } \\
\text { Palmas/TO, entre os } \\
\text { anos de } 2010 \text { e } 2012 \text {. }\end{array}$ & $\begin{array}{l}\text { Compreender os jogos } \\
\text { de poder dentro do } \\
\text { cárcere feminino por } \\
\text { meio de narrativas das } \\
\text { protagonistas }\end{array}$ & $\begin{array}{l}\text { Qualitativa/ } \\
\text { Arquegenealogia } \\
\text { foucaultiana }\end{array}$ \\
\hline SANTA RITA, R. P.; 2006 & $\begin{array}{l}\text { Mestrado em Serviço } \\
\text { Social UnB }\end{array}$ & $\begin{array}{l}\text { Mulheres que } \\
\text { vivenciaram a } \\
\text { maternidade em prisões } \\
\text { dos estados de RJ, SP } \\
\text { e RS }\end{array}$ & $\begin{array}{l}\text { Analisar as ações } \\
\text { institucionais relativas } \\
\text { às experiências de } \\
\text { mulheres presas com } \\
\text { filhos na prisão }\end{array}$ & $\begin{array}{l}\text { Qualitativa/Método } \\
\text { dialético }\end{array}$ \\
\hline LAGO, N. B. de; 2014 & $\begin{array}{l}\text { Mestrado em } \\
\text { Antropologia Social USP }\end{array}$ & $\begin{array}{l}\text { Mulheres encarceradas } \\
\text { em unidades prisionais } \\
\text { da região metropolitana } \\
\text { de São Paulo. }\end{array}$ & $\begin{array}{l}\text { Compreender a } \\
\text { perspectiva que } \\
\text { mulheres aprisionadas } \\
\text { tem em relação à vida } \\
\text { dentro e fora da prisão }\end{array}$ & $\begin{array}{l}\text { Qualitativa/ } \\
\text { Etnografia }\end{array}$ \\
\hline $\begin{array}{l}\text { MIRANDA, M. L. A.; } \\
2016\end{array}$ & $\begin{array}{l}\text { Mestrado em Psicologia } \\
\text { PUC Campinas }\end{array}$ & $\begin{array}{l}41 \text { presidiários } \\
\text { que vivenciam a } \\
\text { paternidade. }\end{array}$ & $\begin{array}{l}\text { Compreender a } \\
\text { experiência emocional } \\
\text { de presidiários } \\
\text { exercendo a paternidade } \\
\text { na prisão. }\end{array}$ & $\begin{array}{l}\text { Qualitativo/ } \\
\text { Abordagem psicanalítica }\end{array}$ \\
\hline SILVA, M. F. da; 2007 & $\begin{array}{l}\text { Mestrado em Psicologia } \\
\text { PUC Campinas }\end{array}$ & $\begin{array}{l}07 \text { presidiários de uma } \\
\text { instituição no interior de } \\
\text { São Paulo }\end{array}$ & $\begin{array}{l}\text { Compreender a relação } \\
\text { entre pais presidiários e } \\
\text { seus filhos na prisão. }\end{array}$ & $\begin{array}{l}\text { Qualitativa/Abordagem } \\
\text { ecológica } \\
\text { Abordagem ecológica }\end{array}$ \\
\hline MODESTI, M. C.; 2011 & $\begin{array}{l}\text { Mestrado em Direito } \\
\text { UFSC }\end{array}$ & $\begin{array}{l}\text { Mulheres encarceradas } \\
\text { em geral }\end{array}$ & $\begin{array}{l}\text { Compreender os } \\
\text { direitos fundamentais } \\
\text { vinculados à mulher } \\
\text { encarcerada e sua } \\
\text { relação com a família }\end{array}$ & $\begin{array}{l}\text { Qualitativa/ } \\
\text { Abordagem ecológica }\end{array}$ \\
\hline
\end{tabular}

Como pode-se inferir da análise do Quadro 01, o método qualitativo foi unânime nessas pesquisas, ocorrendo uma variação de $60 \%$ nas técnicas utilizadas. Sendo assim, a abordagem ecológica e a etnografia apareceram como as técnicas mais utilizadas, sendo cada uma delas empregada em duas pesquisas. 
As amostras encontradas nesses dez trabalhos indicaram, também, que crianças e adolescentes foram estudados em apenas duas ocasiões, em uma dessas pesquisas, focou-se no desenvolvimento delas do ponto de vista de seus familiares e a outra centrou-se na observação dos familiares e profissionais envolvidos no processo de abrigamento. Isto é, mesmo aparecendo como objeto de estudo nessas duas circunstâncias, não tiveram oportunidade de expressar suas opiniões. Majoritariamente, o interesse pelas vicissitudes maternas na prisão, com acentuado recorte de gênero, aparece como $60 \%$ das pesquisas, conforme a Figura 1:

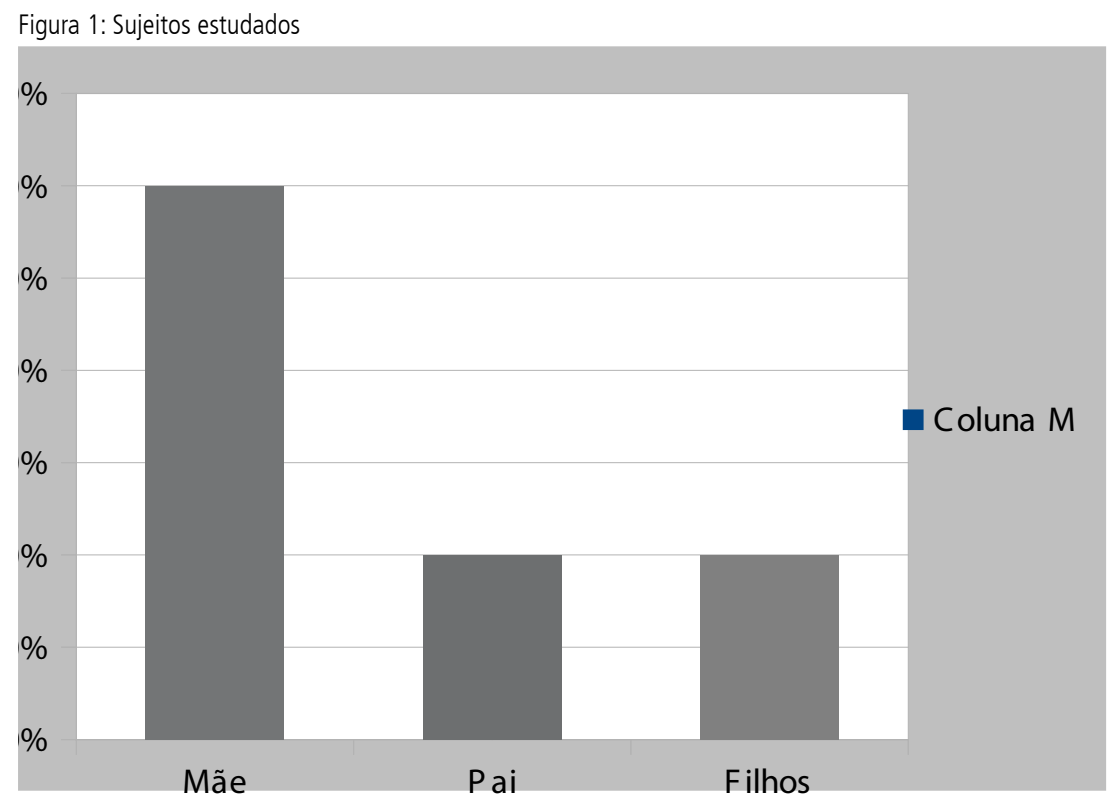

Outra informação relevante que irrompeu dessa metanálise é referente ao envolvimento das instituições de pesquisa com o tema abordado. Em primeiro lugar, $30 \%$ das pesquisas foram desenvolvidas por pesquisadores da PUC de Campinas. Em segundo, aparecem empatadas a UNB, USP e UFSC, com $20 \%$ dos trabalhos cada uma. A UESJMesquita englobou os restantes $10 \%$.

Em relação aos autores utilizados nessas pesquisas, primeiramente, realizou-se um apanhado daqueles que foram citados, no mínimo, em dois estudos e o número de obras mencionadas nas referências bibliográficas. A partir daí, efetuou-se as buscas, em cada pesquisa, do maior número de citações encontradas para cada um deles. Os dados encontrados foram agrupados no Quadro 2 da seguinte forma: 
Quadro 02: Relação de autores e obras mais citados

\begin{tabular}{|c|c|c|c|}
\hline AUTOR & CITAÇÕES NOS TRABALHOS & $\begin{array}{l}\text { NÚMERO DE OBRAS } \\
\text { CITADAS }\end{array}$ & $\begin{array}{l}\text { CONTEÚDO DAS OBRAS } \\
\text { CITADAS }\end{array}$ \\
\hline FOUCAULT, M. & 239 & 16 & $\begin{array}{l}\text { Filosofia, poder e sociedade } \\
\text { metodologia }\end{array}$ \\
\hline FERRAJOLI, L. & 191 & 6 & Direito penal \\
\hline GOFFMAN, E. & 69 & 3 & Punibilidade e sociedade \\
\hline SARLET, I.W. & 48 & 3 & Direitos humanos \\
\hline VERONESE, J. R. P. & 48 & 14 & $\begin{array}{l}\text { Direitos das crianças e } \\
\text { adolescentes }\end{array}$ \\
\hline BARATTA, A. & 44 & 2 & Criminologia e gênero \\
\hline BATISTA, V. M. & 41 & 2 & Punibilidade e sociedade \\
\hline SOARES, B. M. & 41 & 1 & Encarceramento feminino \\
\hline CARVALHO, S. & 40 & 6 & Punibilidade e sociedade \\
\hline $\begin{array}{l}\text { WACQUANT, L. } \\
\text { Fontes: Dados da pesquisa }\end{array}$ & 35 & 2 & Punibilidade e sociedade \\
\hline
\end{tabular}

Por essa informação, verificou-se que os autores mais abordados são aqueles que trabalham a questão da punibilidade em contexto social. Algumas obras, mais especificamente, são voltadas para a questão do gênero e direitos humanos, mas todas perpassam a discussão da punibilidade.

O autor mais citado, como se pode aferir, é o filósofo francês Michel Foucault com 16 obras empregadas nas referências bibliográficas e um total de 239 citações. Por este dado, constatou-se que todo trabalho que objetive discutir as questões da punibilidade como uma demonstração de poder na sociedade, deve remeter-se aos estudos foucaultianos.

Por se tratar de pesquisas de caráter qualitativo, verifica-se que o número de citações é relativamente alto, o que aponta a primordialidade de se buscar um aporte teórico fundamentado e renomado. A Figura 2 apresenta a porcentagem de autores internacionais e nacionais empregados nos trabaIhos, evidenciando que a academia brasileira vem obtendo destaque na produção de obras contendo o tema abordado:

Figura 2

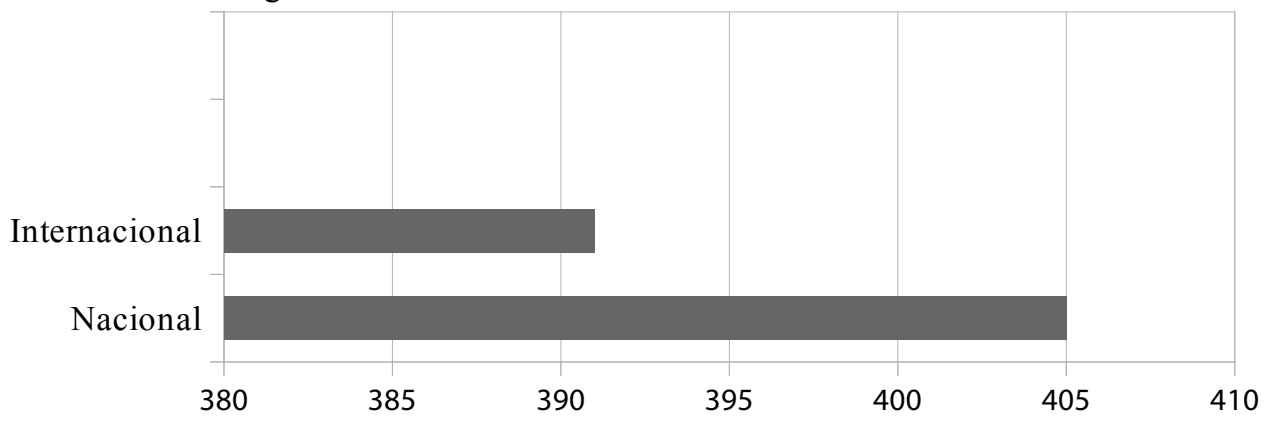




\section{Concluindo a Metanálise: a apresentação dos resultados da pesquisa}

Após o percurso de coleta e análise de dados, torna-se fundamental tornar pública uma síntese dos resultados das teses e dissertações que trataram, de alguma forma, o aprisionamento parental e suas consequências para a família. É neste momento que se compara as diferentes percepções de cada autor, promovendo uma descrição da amostra trabalhada e do recorte idealizado por eles.

Inicia-se, então, pela pesquisa realizada por Silva (2014) que focou sua análise no sofrimento enfrentado por mulheres, mães e chefes de família monoparental, que vivenciaram a experiência do cárcere. Nesse transcurso, a autora descreve o despreparo dos diferentes tipos de profissionais envolvidos na execução penal e as diversas violações de direitos às quais são submetidas essas mulheres no cumprimento da pena, dentre as quais se destaca a interrupção da maternidade. A prisão se configura, assim, como uma instituição fechada, de estrutura formal e burocrática, permeada por medos e preconceitos que apartam a comunicação com a sociedade e perpetuam a estigmatização da família e do condenado, restando à mulher/mãe aprisionada ponderar sobre essas dificuldades e sonhar com um futuro longe das práticas delitivas. Ademais, a autora adverte que o sofrimento dessas mulheres é projetado em seus filhos, ocasionando em ambos danos emocionais, privações afetivas, financeiras, legais, o que resulta no aumento da vulnerabilidade dessa família e a possibilidade de reincidência no crime.

Muitas dessas mães relataram, com pesar, que o estar presa ocasionou a perda de autoridade e o sentimento de impotência frente a criação de seus filhos, visto que, na maioria dos casos estudados, tiveram que contar com uma rede de parentesco ou de amizade para cuidar das crianças. Mesmo assim, passam por momentos aflitivos sabendo que seus filhos podem ser encaminhados para abrigos ou para adoção, no caso de reclusões sucessivas. É neste ponto que Silva (2014) destaca a falta de políticas públicas em apoio às famílias monoparentais separadas pelo aprisionamento materno, resultando vários casos de negligência do poder público em relação a essas crianças e adolescentes privados da convivência com a mãe encarcerada. Outrossim, aqueles que permanecem fora das grades vivenciam situações de estigmatização social e ruptura de vínculos socioafetivos que culminam com a manutenção do ciclo de violência vivenciado por suas mães. Conclui, assim, que " a pena de uma mãe no Brasil não finda em sua pessoa, mas é relegada de herança para seus descendentes" (SILVA, 2014, p.165).

O estudo realizado por Abrão (2010) tratou das relações estabelecidas entre pais encarcerados e seus filhos abrigados, sob a perspectiva do direito à educação e à convivência familiar e comunitária. Em sua opinião, o encarceramento de qualquer um dos genitores provoca uma série de problemas com reflexos sociais, políticos, econômicos e, principalmente, familiar, agravado pelas 
inúmeras violações de direitos praticadas no sistema prisional brasileiro. Nesse cenário, o poder público mostra-se omisso diante das realidades dessas famílias e se esquivam de promover políticas públicas de atendimento aos familiares dos reclusos, chegando ao ponto de descumprir dispositivos legais consolidados no ordenamento jurídico brasileiro que garantem saúde e educação às crianças nascidas nos estabelecimentos prisionais. Por conseguinte, muitas crianças e adolescentes são encaminhadas aos abrigos sendo privados do direito à convivência familiar e comunitária. Esse procedimento tem sido comumente empregado na falta de parentes com condições de oferecer cuidados enquanto os pais cumprem pena de privação de liberdade, feito que evidencia a carência de reformas estruturais no sistema de acolhimento infanto-juvenil.

Dentre essas reformas, urge um projeto político pedagógico que envolva profissionais capazes de fazer a mediação institucional entre o abrigo, a família e a escola. A autora salienta, ainda, que as políticas públicas voltadas para essa parcela da população, quando não recorrem a estratégias equivocadas, tal como manter a criança aprisionada junto da mãe, sob a alegação de assegurar o direito à convivência familiar e comunitária, condenam os filhos dos encarcerados a uma invisibilidade política e social. Assim, conclui que estamos longe de "promover a execução das garantias dos direitos fundamentais de crianças e adolescentes, sobretudo, daqueles marcados pela dupla estigmatização de terem seus pais presos e de viverem em instituições de abrigo" (ABRÃO, 2010, p. 139).

No trabalho de Vieira (2013), percebe-se um recorte de cunho legalista acerca das relações entre mãe e filho em um presídio brasileiro. Ainda que algumas leis nacionais, como a Lei de Execução Penal e as resoluções do Conselho Nacional de Política Criminal e Penitenciária (CNPCP), estabelecerem algumas especificidades ao aprisionamento feminino e, sobretudo ao direito de convivência entre a mãe e o filho nascido na prisão, a prática está longe de garantir condições mínimas a estes usuários. Muitos juízes, atrelados a uma postura conservadora, optam por não aplicar a substituição da prisão preventiva pela prisão domiciliar quando a mulher for imprescindível aos cuidados especiais de criança menor de 6 anos de idade ou com deficiência, ou mesmo quando a mulher for gestante a partir do $7^{\circ}$ mês de gravidez ou sendo esta de alto risco. Mesmo sendo prevista no ordenamento jurídico brasileiro, após ratificadas "Regras de Bangkoc", a substituição permanece ignorada pelos magistrados que preferem manter a execução da pena feminina emparelhada aos moldes da masculina.

As unidades prisionais femininas tornam-se, assim, meras adaptações dos presídios masculinos, sem estrutura especifica para abrigar mulheres e seus filhos, permeadas por violências e desconstrução da encarcerada enquanto mulher. A autora constatou, ainda, que o número de crianças que vivem no 4 Regras das Nações Unidas para o Tratamento de Mulheres Presas e Medidas Não Privativas de Liberdade para Mulheres Infratoras. 
cárcere com sua mãe aumenta a cada dia e enfrentam situações cotidianas que impedem seu desenvolvimento adequado, mesmo tendo a garantia legal que a pena não passa da pessoa do condenado. Dessa maneira, Vieira (2013) destaca que as garantias instituídas no Estatuto da Criança e do Adolescente pelo paradigma da Proteção Integral, que transformou as crianças e adolescentes em sujeitos de direitos fundamentais devidos pelo Estado, pela família e pela sociedade, são descaradamente descumpridas pelo próprio Estado quando este não formula políticas públicas voltadas para o convívio de uma criança com sua mãe no interior de uma prisão.

A realidade prisional faz com que a infância encarcerada seja vivenciada de forma particular, ou seja, com as especificidades de uma vida moldurada pela violência, pela preocupação absoluta com a segurança e pela preservação da disciplina que caracterizam o encarceramento da mãe (VIEIRA, 2013, p. 383).

Não poderia ser diferente a conclusão de que o estabelecimento prisional é inapropriado por não oferecer os estímulos necessários ao desenvolvimento da criança e negar-lhes o direito à saúde, educação e segurança. Destarte, comprovou-se que o encarceramento da mãe coloca à prova a efetivação da Doutrina da Proteção Integral e impacta profundamente o desenvolvimento físico, mental e emocional de seus filhos.

A pesquisa de Beckman (2007) trouxe à luz o desenvolvimento de crianças em idade pré-escolar, que tem seus pais encarcerados, e experimentam um sentimento de exclusão moral e social. Segundo a autora, o sistema penitenciário brasileiro não possui políticas públicas que trabalhem a recepção e a convivência dessas crianças nas unidades prisionais no dia de visita, fator que leva muitas famílias a proibirem essas visitas, por acreditarem estar protegendo suas crianças de um ambiente que não está preparado para recebê-las. Tragicamente, essas famílias não compreendem que manter o elo da criança com o pai aprisionado é um fator de proteção emocional que evita a perda do vínculo afetivo entre eles. Os familiares, por sua vez, relataram que as crianças demonstram sofrimento emocional com a problemática das filas e revistas nas entradas dos presídios, além de se sentirem, muitas vezes, humiIhadas pelos agentes penitenciários. Dessa maneira, Beckman (2007) considera que a maneira como a família lida com o assunto da prisão paterna pode ser considerado um fator de risco, pois, se os familiares não falam abertamente sobre esse fato, ocasionam nessas crianças sentimentos de rejeição, de medo, de desconfiança, ou, no caso de saberem por terceiros, preconceito e exclusão.

Também foi constatado que a escola não está preparada para lidar com a realidade dessas crianças e que, em alguns casos, as próprias educadoras reproduzem os discursos sociais, contribuindo para o processo de estigmatização. Neste sentido, a autora avalia como sendo positivo o fato de sua pesquisa ter proporcionado às educadoras um olhar diferente em torno dessa questão, 
permitindo a abertura de um espaço de discussão sobre o desenvolvimento de crianças que vivem em condição de risco e viabilizando a função social da educação infantil de proteção dessas crianças. Esses novos olhares rompem com o ciclo de violência e proporcionam um desenvolvimento sócio-emocional, podendo servir como uma parte do processo de mudança dessa realidade e

possibilitando à escola buscar um outro olhar sobre esta questão, planejando projetos pedagógicos mais compatíveis com os aspectos simbólicos, culturais, educativos e econômicos das comunidades onde as crianças moram e também, por meio de políticas públicas voltadas para as famílias de presidiários para que possam acabar com o processo que cria, multiplica e produz socialmente a pobreza (BECKMAN, 2014, p. 72-73).

Quadrado (2014) realizou seu estudo com presidiárias do estado de Tocantins no período de 2010 a 2012, tomando por referência a construção de narrativas por meio do método arquigenealógico de Michel Foucault. A caracterização autobiográfica trabalhada pela autora apresentou a multiplicidade de mulheres presentes no crime e na prisão que, embora tenham pouca idade, já experimentaram a maternidade e anseiam voltar ao convívio familiar. Muitas delas, com filhos ainda nos primeiros anos de vida, testemunharam que valores e princípios, tanto familiares como religiosos, não influenciaram suas histórias de vida, mas reconhecem que o tempo desprendido no cárcere as privou de uma parte essencial da maternidade: participar do crescimento dos filhos e desenvolver, juntamente deles, os vínculos afetivos. Segundo Quadrado (2014), o resultado final de sua pesquisa a fez constatar que a concepção de poder das perspectivas sistêmicas é insuficiente para explicar relações de poder no sistema prisional, dado que não se consegue estruturar uma perspectiva radicalmente simétrica de distribuição do poder, obrigando as presidiárias a conviverem com as assimetrias, resistências, coações, com os conflitos e interesses desencadeados pelos seus processos internos.

O trabalho de Santa Rita (2006) também foi direcionado para as ações institucionais em torno da mulher encarcerada que é mantida junto ao seu filho. A autora afirma que essa temática vem sendo silenciada e não pautada de forma efetiva na agenda pública, decorrendo, assim, a inexistência de leis, normas, planos e outros instrumentos que possam servir para a proteção e para a defesa de direitos humanos. Em sua opinião, as crianças que permanecem com suas mães no presídio estão, na verdade, encarceradas e essa condição afronta o inciso XLV do artigo $5^{\circ}$ da Constituição Federal que preconiza que a pena não poderá passar da pessoa do condenado. $O$ estudo mostrou que, no Brasil, o aumento do número de mulheres na prisão é inversamente proporcional às especificidades do gênero, dado que perdura a ausência de espaços físicos voltados para atendimento da mãe presa com seus filhos. Constata-se que quase metade das mulheres presas no sistema penitenciá- 
rio brasileiro está inserida em alas ou celas femininas existentes em unidades masculinas, sendo que há estados brasileiros que não possuem unidades exclusivas para mulheres em cumprimento de pena. A isso, soma-se o fato dos instrumentos legais e normativos de proteção à mãe presa, ratificados pelo Estado, não serem cumpridos na maioria dos estados brasileiros, corroborando a inexistência de berçários nas unidades prisionais e relegando as crianças às celas de suas mães, muitas vezes junto a outras mulheres que não necessariamente estão na mesma condição. Nas poucas penitenciárias com berçário e creche instalados, descortina-se o descumprimento das normas da Política de Educação Infantil, sem nenhuma ação pedagógica, demonstrando o descaso dos estados com a saúde, a educação, o psicológico e o social dessas crianças encarceradas. Ademais, os profissionais que atuam no atendimento às mães presas e suas crianças são, de uma forma genérica, numericamente insuficientes e não vinculados às áreas específicas como ginecologia, pediatria, nutrição e educação infantil. Soma-se a isso que o tempo mínimo instituído por lei para que as mães presas possam permanecer com seus filhos durante o período de aleitamento materno é muitas vezes negado ou estipulado conforme o arbítrio dos dirigentes e/ou a discricionariedade da gestão prisional.

As ações institucionais vêm se desenvolvendo sem nenhum planejamento que leve em consideração a humanização da execução penal. São precárias, isoladas, pontuais e têm contribuído para a degradação e violação do direito a uma vida digna (SANTA RITA, 2006, p. 150).

Acerca da quebra dos vínculos familiares pelo aprisionamento parental, a autora salienta que esta se dá de forma mais concreta em situações de encarceramento feminino, tornando essas mulheres ainda mais vulneráveis pela situação da perda de seu papel como mulher, esposa, mãe e filha. Se por um lado a presença dos filhos é percebida como um abrandamento da pena, por outro, a separação das crianças é sentida como uma das piores perdas na prisão, gerando uma ambiguidade de sentimentos em relação à permanência dos seus filhos em ambiente prisional.

Por sua vez, Modesti (2011) realizou uma pesquisa de revisão bibliográfica na qual aborda as mazelas que envolvem as mulheres aprisionadas, sobretudo no que diz respeito à violação de seus direitos fundamentais e de sua vivência como mãe. A autora fez uma interligação entre a prisão feminina e a questão social que envolve a mulher, o cárcere e a família. Seu estudo perpassou várias concepções teóricas sobre direitos humanos e a complexidade da execução penal para as mulheres. Para ela, está clara a existência de uma certa seletividade do sistema de justiça criminal que está longe de fornecer proteção, segurança e justiça, atuando como verdadeira manifestação de poder e instrumento de dominação. Seu estudo foi perspicaz ao traçar um perfil social das mulheres encarceradas no Brasil: mulheres jovens, de origem social me- 
nos favorecida, baixo grau de escolaridade e que estão cumprindo pena por envolvimento com o narcotráfico. A maioria delas é composta de mães que experimentam um sofrimento angustiante ao serem separadas de seus filhos e encontrar um poder público que desconsidera as características das mulheres encarceradas e suas relações familiares, sustentando um sistema prisional que consagra as desigualdades sociais e de gênero.

Se o Estado tem que assegurar a convivência familiar e comunitária da criança e do adolescente e protegê-los contra as mais diversas formas de violência, opressão, crueldade, discriminação, negligência, o que se tem a dizer sobre a situação do número, cada dia mais elevado, de famílias que se rompem, fragmentamse, decompõem-se diante das prisões de tantas mulheres/mães? (MODESTI, 2011, p. 231).

Lago (2014) optou por um recorte de gênero ao pesquisar a visão de quatro mulheres que vivem em privação de liberdade e como o encarceramento se expande para seus relacionamentos sociais, sobretudo os familiares. A autora relata que foi necessário trabalhar os processos mediativos com as outras presas, com a instituição prisional e até mesmo com o PCC, para entender a dinâmica da vida dessas mulheres no presídio. Algumas delas constituem noções de família que se contrapõem aos olhares do sistema de justiça, mas não deixam de dialogar com os papéis e expectativas destinados a elas. Outras lutam para sair do sofrimento que é estar isolada no cárcere, partindo para apoio religioso. "O gênero é um marcador que perpassa os relatos das quatro personagens, mas se articula à situação social dessas mulheres, pobres", (LAGO, 2014, p. 89). Para a autora, o gênero constitui a dinâmica vivenciada na prisão e ganha sentido diante das expectativas referentes às classes das presidiárias.

Já Miranda (2016) elegeu um recorte voltado para o olhar masculino em torno paternidade vivenciada de dentro de uma prisão. A partir dos relatos dos participantes, a autora pôde descobrir um sofrimento compartilhado por pais, filhos e demais familiares, comprovando sua hipótese de que o encarceramento de um pai configura-se em fator de risco para a manutenção do relacionamento entre pais reclusos e seus filhos. Levando-se em consideração que muitas vezes essa relação já encontrava-se prejudicada antes da reclusão, a autora defende que a quebra de vínculo familiar compromete o bem estar emocional de ambos e a reintegração social do preso. Por outro lado, sinalizou os potenciais benefícios da manutenção do relacionamento entre pais encarcerados e seus filhos, assim como os fatores pessoais, familiares e institucionais que podem inibir ou facilitar a vinculação afetiva, tomando o cuidado de advertir que existem exceções. A partir disso, recomenda que outros pesquisadores promovam estudos que auxiliem o envolvimento afetivo de pais encarcerados com seus filhos, salvo quando as circunstâncias condenarem esse tipo de aproximação. 
Tais ações poderiam incluir grupos de orientação para o exercício da paternidade na prisão, além do aconselhamento psicológico e uma área de visitação diferenciada, a fim de preservar os laços familiares (MIRANDA, 2016, p.109).

Também centrada no aprisionamento paterno, a pesquisa de Silva (2007) realizou reflexões e investigações acerca da problemática que envolve o pai que é presidiário e suas percepções sobre da ação do Estado em sua vida e na vida de seus filhos. Ela buscou verificar o funcionamento das políticas públicas penais no Estado de São Paulo, voltadas para a condição paterna, e encontrou uma sequência de dificuldades e rupturas comandadas pelas necessidades e exigências da instituição prisional e do sistema social, levando-a a admitir que a entrada na prisão resulta numa série de perdas para o condenado, tais como a supressão total ou parcial dos benefícios sociais e o vínculo afetivo com os filhos. Ademais, o desamparo econômico-social ao qual é relegada essa família, que em sua maioria está classificada nas camadas mais pobres, aumenta a fragilidade das relações e vínculos afetivos e termina por distanciar o familiar do detento, aumentando seu sofrimento. Seus resultados comprovaram que a prisão, instituição comprovadamente despreparada para lidar com questões familiares, gera impactos profundos na relação pai-filho e na família como um todo.

\section{Considerações finais}

Ao chegar ao fim dessa metanálise, acredita-se que a revisão sistemática realizada no lapso temporal de dez anos, qual seja, de 2006 a 2016, contribuiu para elucidar como a academia brasileira vem trabalhando as implicações do aprisionamento parental em diversos âmbitos. Além disso, propiciou uma quantidade de informações que auxiliam na propositura e justificativa de outras pesquisas dentro dessa temática.

As dez pesquisas encontradas e analisadas revelaram que o método de pesquisa unânime é o qualitativo, ocorrendo variações nas técnicas empregadas. Destas, a etnografia e a abordagem ecológica foram as mais utilizadas. Não foram encontradas pesquisas que utilizam o Método Clínico Piagetiano na coleta e análise dos dados, fato que garantirá a uma nova pesquisa um diferencial na abordagem do tema.

As amostragens propostas pelos dez pesquisadores centraram em mães ou pais aprisionados, não sendo possível encontrar nenhum trabalho que trouxesse o ponto de vista dos filhos dos encarcerados. Esse dado encoraja a propositura de projetos de pesquisa que concentrem-se no olhar daqueles que não tem voz e se encontram do outro lado das grades, vivenciando em seu dia a dia os preconceitos e amarguras de se ter um familiar aprisionado.

A análise do referencial teórico direcionou a uma relação dos dez autores mais citados, com destaque para FOUCAULT, M., com 239 citações. Apesar disso, o número de obras nacionais foi superior a internacional, corroborando a percepção 
de que a academia brasileira tem voltado seus interesses à questão da punibilidade no ordenamento jurídico brasileiro e o tratamento social em torno da pena.

Pretende-se, assim, que este artigo possa fomentar na comunidade acadêmica brasileira o interesse por um assunto deveras delicado, tanto para a família como para a sociedade, e que outros pesquisadores possam embrenharse por esse tema, arrebatando-o do limbo dos estigmas sociais e apresentando novos atores dessa malfadada história.

\section{Referências}

$A B R A \tilde{O}, M$. J. As implicações do aprisionamento dos pais no direito à educação e à convivência familiar e comunitária de crianças e adolescentes em regime de abrigo na cidade de São Paulo. São Paulo, 2010. Dissertação (Mestrado em Educação) - Faculdade de Educação, Universidade de São Paulo.

BECKMAN, M. V. R. Crianças pré-escolares e prisão paterna: Percepção de familiares. Campinas, 2007. Dissertação (Mestrado em Psicologia) - Centro de Ciências da Vida, Pontifícia Universidade Católica de Campinas.

COOPER, Harris. Research synthesis and meta-analysis: A step-by-step approach. 3. ed. Thousand Oaks, CA, Sage, 2010

LAGO, N. B. do. Mulheres na prisão: Entre famílias, batalhas e a vida normal. São Paulo, 2014. Dissertação (Mestrado em Antropologia Social) - Faculdade de Filosofia, Letras e Ciências Humanas, Universidade de São Paulo.

LEGRAMANTI, C. ; KLARMANN, P. Metanálise: Um Guia Prático. Clinical \& Biomedical Research, v. 30, n.04, p. 436-447, 2011.

MIRANDA, M. L. A. Narrativas Interativas de presidiários sobre a experiência da paternidade. Campinas, 2016. Dissertação (Mestrado em Psicologia) - Centro de Ciências da Vida, Pontifícia Universidade Católica de Campinas.

MODESTI, M. C. As Mulheres aprisionadas e os reflexos familiares decorrentes do cárcere. Florianópolis, 2011. Dissertação (Mestrado em Direito) - Universidade Federal de Santa Catarina.

QUADRADO, J. C. Fragmentos de uma genealogia de mulheres no contexto prisional: Um estudo de relatos sobre a experiência de aprisionamento. Brasília, 2015. Tese (Doutorado em Sociologia) Departamento de Sociologia, Universidade de Brasília.

ROSCOE, D. D.; JENKINS, S. A. Meta-Analysis of Campaign Contributions' Impact on Roll Call Voting. Social Science Quarterly, v. 86, n. 1, p. 52-68, 2005.

SANTA RITA, R. P. Mães e crianças atrás das grades: Em questão o princípio da dignidade da pessoa humana. Brasília, 2006. Dissertação (Mestrado em Política Social) - Departamento de Serviço Social, Universidade de Brasília.

SILVA, A. D. Mãe / Mulher atrás das grades: A realidade imposta pelo cárcere à família monoparental feminina. Franca, 2014. Dissertação (Mestrado em Serviço Social) - Faculdade de Ciências Humanas e Sociais, Universidade Estadual Paulista (UNESP).

SILVA, M. F. da. Presidiários: Percepções e sentimentos acerca de sua condição paterna. Campinas. 2007. Dissertação (Mestrado em Psicologia Escolar). Centro de Ciências da Vida - Pontifícia Universidade Católica de Campinas.

VIEIRA, C. M. C. do A. Crianças encarceradas - a proteção integral da criança na execução penal feminina da pena privativa de liberdade. Florianópolis, 2013. Tese (Doutorado em Direito). Universidade Federal de Santa Catarina. 